\title{
The thymic repertoire of neuroendocrine self-antigens: physiological implications in T-cell life and death
}

\section{Henri Martens, Béatrice Goxe and Vincent Geenen}

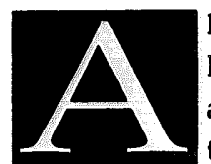

Ithough the thymus has long been considered to be a part of the endocrine system, it is difficult to apply the model of endocrine cell-cell signalling to the process of intrathymic T-cell differentiation. This might be due, at least in part, to the importance of the thymus as the primary lymphoid organ responsible for T-cell differentiation, such that its immune properties have overshadowed its endocrine role. However, these two functions are intimately linked, and neuroendocrineimmune interactions in T-cell education liave important physiological and pathological implications.

\section{The neurohypophysial hormone family}

The neurohypophysial (NHP) hormones constitute a family of nonapeptides that are highly conserved throughout evolution ${ }^{1}$ and all have cysteine residues in positions 1 and 6 forming a disulfide bridge. They can be divided in two lineages corresponding to the oxytocin (OT)-like and vasopressin (VP)-like peptides. Both of the lineages are thought to have arisen from the duplication of a single ancestral gene ${ }^{1}$. In mammalian vertebrates, OT-like peptides are implicated in the control of reproduction, whereas VP-like peptides regulate water homeostasis and also have some cardiovascular functions. All known NHP hormones are synthesized as larger precursors containing a neurophysin domain $( \pm 10 \mathrm{kDa})$, the biological function of which remains unclear.

\section{Thymic NHP-related signals}

As early as 1910, Ott and Scott showed that thymic extracts could induce milk ejection (galactokinesis) when injected into goats. The causative agent was identified by du Vigneaud's group in the 1950s as OT. Subsequent studies have confirmed that thymic epithelial cells (TEC) from human and different animal species ar ? a site of synthesis of peptides related to the NHP family, with marked dominance for those of the OT lineage $\mathrm{e}^{2-5}$. Using various polyclonal and monoclonal antibodies (mAbs) against different epitopes of the NHP family, we confirmed that the dominant thymic NHPrelated epitope belongs to the OT lineage although both pro-OT and pro-VP gene transcripts are detected at low levels within human and murine thymus extracts ${ }^{6}$. A striking example of the intimate neuroendocrine-immune interactions within the thymus is provided by thymic nurse cells (TNC), which synthesize NHP-related peptides and express on their surface markers of the neuroendocrine system such as A2B5 and neuron-specific enolase ${ }^{7}$. Primary cultures of TEC/TNC do not secrete NHPrelated peptides and a recent ultrastructure study confirmed the presence of immunoreactive (IR)-OT in the cytosol, clear vesicles and perimembrane space of murine TEC/ TNC, but not within large dense secretory granules such as those in the hypothalamo-NHP axis ${ }^{8}$. A nonclassical distribution of NHPrelated mRNA and peptides has also been detected in eosinophils of the mouse spleen'.

The term 'cryptocrine' has been introduced in endocrinology to describe a particular type of cell-cell interaction ${ }^{10,11}$. Cryptocrine cell-cell signalling occurs in microenvironments characterized by large 'nursing' epithelial cells (like TEC/TNC in the thymus or Sertoli cells in the testis) that enclose the cell populations ( $T$ cells and spermatids, respectively) that differentiate in close vicinity of these 'nurse' cells.

\section{Thymic NHP peptide receptors}

Functional NHP-type receptors are expressed by a variety of T-cell lines ${ }^{12-15}$, with a predominance of V1-type receptors on pre-T cells (murine $\mathrm{RL}_{12}$-NP cell line) and OT-type receptors on differentiated cytotoxic $\mathrm{T}$ cells (murine CTL- $\mathrm{L}_{2}$ cells) ${ }^{12}$. Two recent studies also found an NHP peptide receptor of the V1b subtype in the human and rat thymus ${ }^{16,17}$

Within the thymic microenvironment, the physicochemical conditions are conducive to functional cryptocrine signalling between TEC/TNC and pre-T cells ${ }^{12}$. Moreover, NHP peptides increase tritiated 


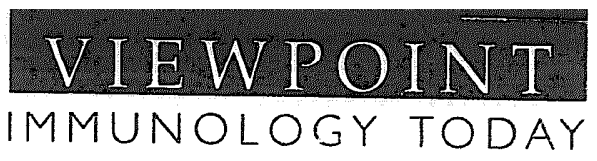

thymidine $\left(\left[{ }^{3} \mathrm{H}\right] \mathrm{TdR}\right)$ incorporation into freshly isolated murine and human thymocytes ${ }^{12}$ and induce the phosphorylation of the focal adhesion kinase p125 ${ }^{\mathrm{FAK}}$ (Ref. 18) (H. Martens et al., unpublished). Thus, there are considerable data supporting thymic cryptocrine signalling mediated by NHP-related peptides.

\section{Thymic OT as the self-antigen of the NHP family}

In the thymus, cryptocrine signalling is intimately associated with the presentation of self-antigens to developing $\mathrm{T}$ cells. This action was long thought to be mediated by interdigitating thymic cells only, but there is now evidence that TEC/TNC are also actively involved in the thymic induction of immunological self-tolerance ${ }^{19}$. At the molecular level, major histocompatibility complex (MHC) class I molecules are involved in central tolerance since they present peptides derived from the processing of endogenous proteitis to the T-cell receptor (TCR) on CD8 ${ }^{+} \mathrm{T}$ cells ${ }^{20}$. The OT amino acid sequence CYIQNCPLG possesses appropriately positioned hydrophobic tyrosine $(\mathrm{Y})$ and leucine $(\mathrm{L})$ residues, which permit it to be anchored to the groove of some MHC class I molecules ${ }^{21}$. Therefore, it is hypothesized that in human and other mammalian species, thymic OT is the self-antigen of the NHP family.

\section{The biochemical pathways leading to the presentation of OT by TECITNC}

Human TEC surface membranes were purified by ultracentrifugation and dissolved in a non-ionic detergent. The solution was then run down an affinity column prepared with a mAb dis:cted to human MHC class I molecules. Following SDS-PAGE, instead of the expected $45 \mathrm{kDa}$ fractions (the molecular mass of MHC class I heavy chain), western blot analyses revealed a $55 \mathrm{kDa}$ fraction that could be labelled both by anti-MHC class I $\mathrm{mAb}$ and by an antiserum against the highly conserved part of neurophysins. This protein was still present after mercaptoethanol and/or heat denaturation, and the antiserum to neurophysin did not recognize $\beta$-microglobulin. Given these data, we interpret the thymic membrane $55 \mathrm{kDa}$ protein as a chimeric or a hybrid precursor including neurophysin- $(10 \mathrm{kDa})$, as well as MHC class I heavy chain $(45 \mathrm{kDa})$ related domains. This $55 \mathrm{kDa}$ protein differs from the hypothalamic OT precursor $(16 \mathrm{kDa})$ and probably reflects a strong binding of the neurophysin domain to MHC class I heavy chain at a posttranscriptional level ${ }^{22}$.

Until recently, the binding of OT or VP to neurophysins for transport along the NHP axis provided a useful model for studying the interaction of a short peptide with a larger protein. Several studies have pointed out the importance of the tyrosine residue in position 2 of OT and VP for this binding ${ }^{23,24}$. Analogous biochemical principles seem to rule the binding of antigens to the groove of some MHC class I molecules, including the presence of a tyrosine residue in position 2 (Ref. 21). So, by analogous binding, neurophysin transports $\mathrm{OT}$ along axons of the NHP axis while the neurophysin domain of the TEC membrane chimeric $55 \mathrm{kDa}$ protein could be implicated in the presentation of thymic OT to pre-T cells.

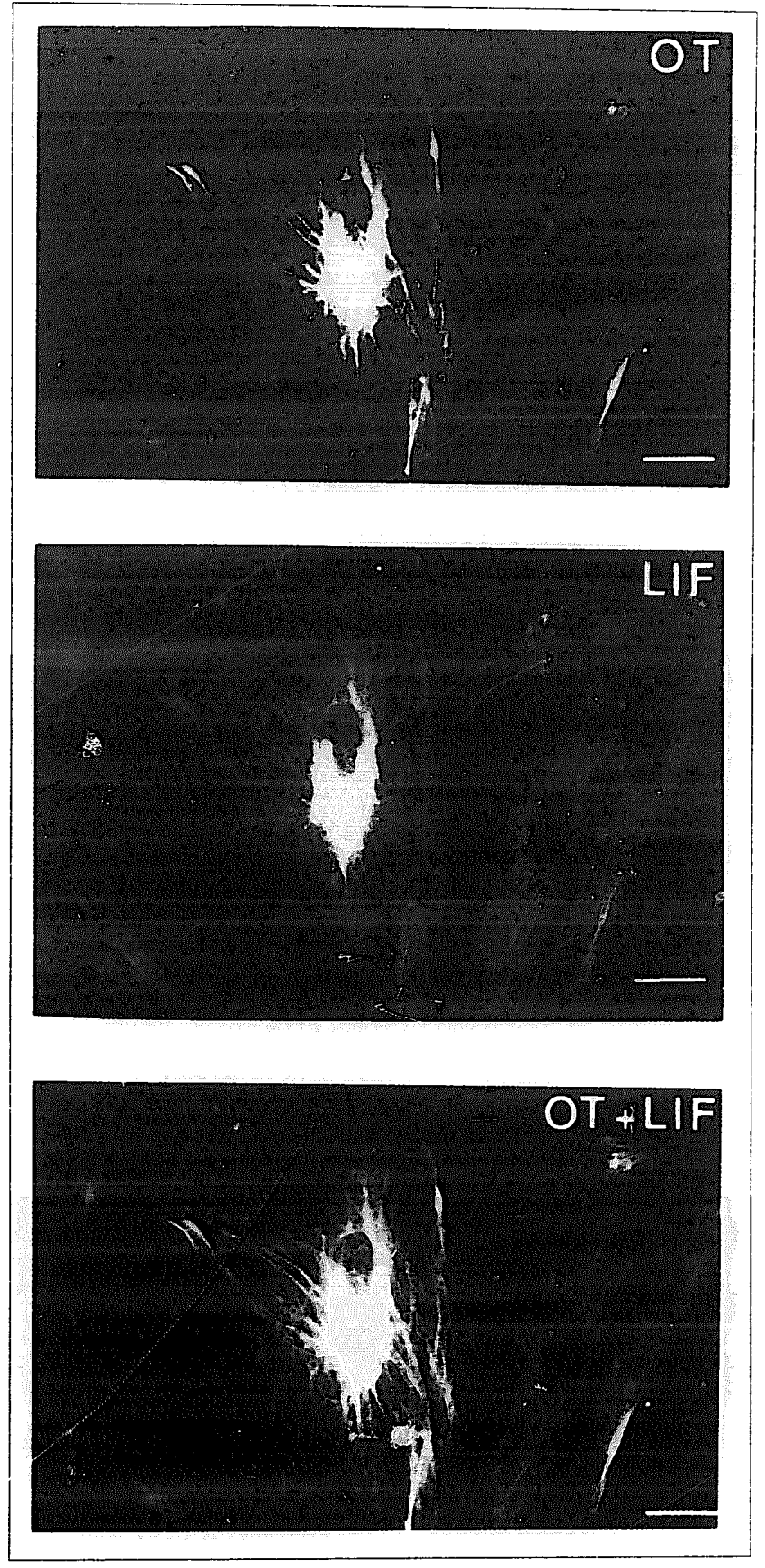

Fig. I. Colocalization of IR-OT with IR-LIF in human TEC after 21-day culture. Immunofluorescence staining was obtainet with anti-OT (green) $m A b$ O33 and anti-LIF (red) antiseratm. The locer frame is a superimposed image of OT and LII immunostaining. Yelloul'-orngere indicates an overlap of IR-OT and IR-LIF. Bar is $10 \mu \mathrm{m}$. Abbreciations: IR, immunoreactive; LIF, leuka'mia inhibitory factor; OT, oxyfocin.

Although thymic MHC class I pathways are involved in the process, it appears that TEC/TNC T-cell education to OT is not restricted in an allelic fashion in contrast with the peripheral presentation of alloantigens by dedicated antigen-presenting cells.

\begin{tabular}{|c|c|}
\hline V० 1.17 & N 0.7 \\
\hline
\end{tabular}




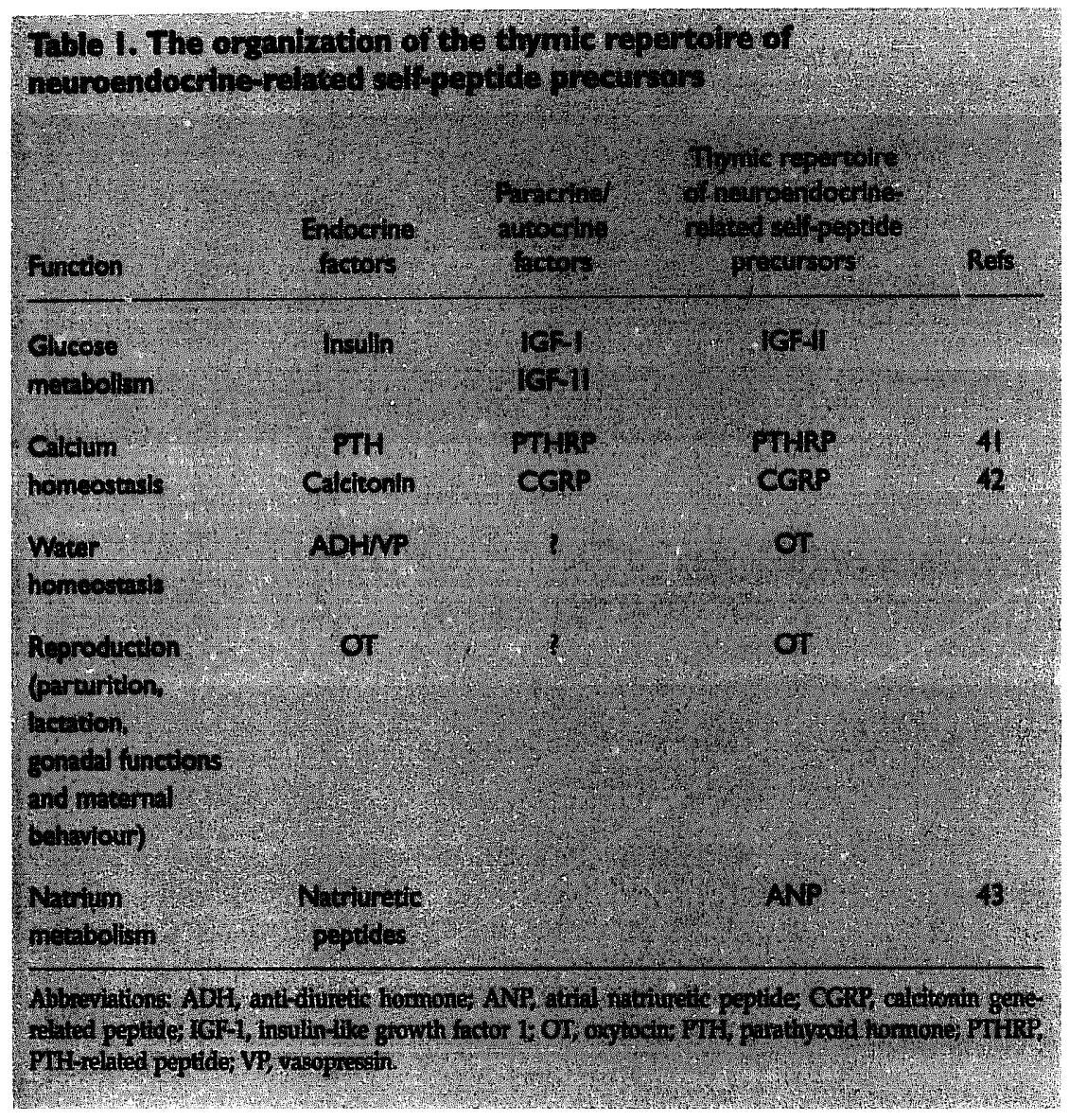

Another selective advantage resides in the potential presentation of the characteristic cyclic structure of the NHP family to pre-T cells. In addition to our findings, a tecent study also suggests a distinction between thymic T-cell education and antigen-presenting function $\mathrm{s}^{25}$.

Furthermore, our most recent results show that OT is colocalized in human cultured TEC with interleukin $1 \beta$ (IL-1 $\beta$ ), IL-6 and leukaemia-inhibitory factor (LIF) (Fig. 1). Oxytocin is specifically recognized at the outer surface of human TEC by $\mathrm{mAbs} \mathrm{O} 13$ and $\mathrm{O} 33$ directed against the linear C-terminal and the cyclic part of the OT molecule, respectively; this recognition markedly enhanced the secretion of IL- 6 and LIF (but not IL-1 $\beta$ ) by primary cultures of human TEC, while the addition of mAbs to VP did not exert any effect ${ }^{4+}$. These data provide strong evidence of the full processing of OT expressed at the outer surface of the TEC membrane, and support the hypothesis of thymic OT as the self-antigen of the NHP family.

\section{Self-antigens of tachykinin and insulin families}

Neurokinin A (NKA) is the peptide of the tachykinin family encoded by the preprotachykinin $\mathrm{A}(P P T-A)$ gene in human and rat TEC (Ref. 26). Thymic PPT-A expression was shown to be glucocorticoid dependent since adrenalectomy of Sprague-Dawley rats markedly enhanced the levels of thymic PPT-A mRNA (A. Ericsson and V. Geenen, unpublished). In contrast to other members of the tachykinin family, NKA also exerts mitogenic effects on murine thymocytes. This IL-1-type bioactivity of NKA suggests an interaction with specific receptors expressed by pre-T cells that could be another accessory pathway in T-cell maturation. The amino acid sequence of NKA (HKTNSFVGLM) has the same C-terminal epitope as other members of the tachykinin family. This epitope possesses a leucine residue in position 9 that could be used in the binding to some MHC class I molecules; thus NKA can be predicted to be a T-cell epitope.

We have recently shown that insulin-like growth factor II (IGF-II) is one peptide of the insulin family that is expressed by human and rat TEC/TNC (Ref. 27). IR-IGF-I is also detected in human and rat thymus extracts but in lower concentrations. Although IRIGF-II is expressed by TEC/TNC, it is not secreted into the supernatant of human or rat primary TEC cultures. Interestingly, overexpression of IGF-II in transgenic mice was shown to induce thymic hyperplasia and to increase thymic cellularity ${ }^{28}$. Our recent studies have shown that IR-IGF-II can be detected in confocal microscopy at the outer surface of human TEC membranes and thus can be presented to pre-T cells during their differentiation (I. Achour $c t$ al., unpublished). The question of a central T-cell tolerance of the insulin family is of major physiologic al significance since it could lead to T-cell tolerance of many components of the pancreatic islet $\beta$ cell, the site of synthesis and endocrine secretion of insulin, and the target of diabetogenic insulitis.

\section{T-cell tolerance of neuroendocrine families: implications in pathogeny of autoimmune endocrine diseases}

Since the dominant thymic peptide of the NHP family belongs to the OT lineage, it is logical to conclude that the OT-mediated neuroendocrine functions are better tolerated than the VP-mediated ones. Thus, a strong immunological tolerance protects the OT lineage, rather than the VP one, from autoimmune aggression. Indeed, some cases of idiopathic diabetes insipidus have been shown to result from an autoimmune hypothalamitis specifically oriented toward VP-producing neurons ${ }^{20,30}$. Given the importance of the OT lineage in the control of several levels of the reproductive process (parturition, maternal behaviour, lactation and paracrine regulation of gonadal functions), a stronger tolerance of this lineage is expected to be crucial for the preservation of the species. So, in the NHP family, OT behaves as the self-antigen, while VP could be the prospective 


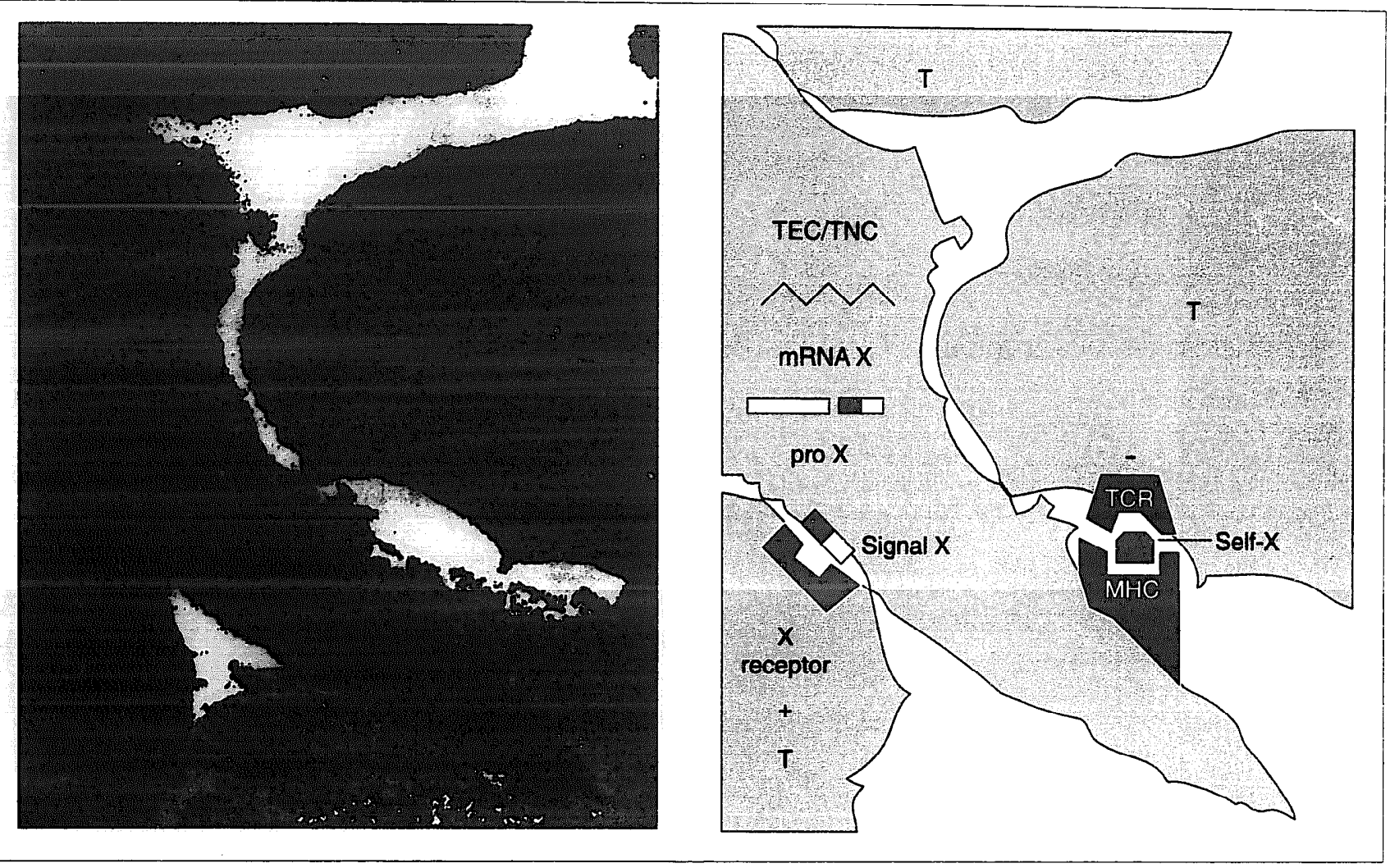

Fig. 2. Ultrastructural image from the murine thymic cortex. Pre-embedding labelling with polyclonal anti-OT K31 at 1:700 (G. Jirikowsky, Munich) and peroxidase-anti-peroxidase. Diffuse IR-OT appears in the cytosol of a TEC/TNC process of the subcortical area with ramifications among packed thymocytes (T). Some points of focal adhesion can be observed between TEC and T cells: $T$ cells appear as though they were' suckling' the IR-OTproducing TEC/TNC. The economical principle of the model is based upon the homology of peptide sequences between endocrine signals and related thymic peptides that are synthesized by TEC/TNC and presented to the differentiating T cells. This homology strongly supports a dual role for the thymic repertoire of neuroendocrine precursors (pro X). First, they constitute a tolergenic source of neuroendocrine self-antigens (self-X). These self-antigenic sequences are highly conserved throughout evolution of their family. On the other side, thymic neuroendocrinc-related precursors are the source of signals (signal $X$ ) that provide accessory pathways in the process of $T$-cell positive selection following their interaction with neuroendocrine-type receptors ( $X$ receptor) expressed by developing $T$ cells. Abbreviations: IR-OT, immunoreactive oxytocin; $M H C$, major histocompatibility complex; TCR, T-cell receptor; TEC, thymic epithelial cells; TNC, thymic nurse cells.

target autoantigen of autoimmune processes. An infiltration of the hypothalamo-NHP tract by inflammatory mononuclear cells has been repeatedly observed, either after active immunization against VP (Ref. 31) or in spontaneous autoimmune diabetes insipidus ${ }^{30}$. Together, these data support the idea that hypothalamic neurons express some surface antigens representative of their neurosecretory activity.

The breakdown of immunological tolerance of endocrine pancreatic islet $\beta$ cells is becoming increasingly recognized as a major etiopathogenic event in the emergence of autoimmune insulindependent diabetes mellitus (IDDM) ${ }^{32}$. This breakdown is thought to be followed by an autoimmune cascade of events leading finally to the disappearance of insulin-secreting islet $\beta$ cells; consequently insulin is more often accepted as a major autoantigen of the diabetogenic autoimmune process. The sequence 7-15 (CGSHLVEAL) from the B domain of bovine insulin has been identified as a target autoantigen for $\mathrm{H}-2 \mathrm{~K}^{\mathrm{b}}$-restricted cytotoxic $\mathrm{T}$ cells ${ }^{33}$. However, the biochemical identity between this insulin-derived autoantigen and the corresponding sequence of IGF-II (CGGELVDTL) is not complete. This difference in amino acid sequence could be important for the nature of the T-cell responses (activation vs. tolerogenic effect) elicited either by insulin- or IGF-II-derived peptide sequences. As a further argument for its tolerogenic properties, the production of IGF-II-specific antibodies is known to be more difficult than those specific for IGF-I (Ref. 34). Thymic IGF-II expression in diabetes-prone and diabetes-resistant $B B$ rats is under current investigation to elucidate its precise role in the pathogenesis of IDDM.

\section{Evolutionary aspects of neuroendocrine-immune interactions}

During the evolution of the endocrine system, varicus forms of cell-cell signalling have appeared: (1) the primitive stages of

\begin{tabular}{llllll}
\hline & 01.17 & N 0.7 & 3 & 15
\end{tabular}




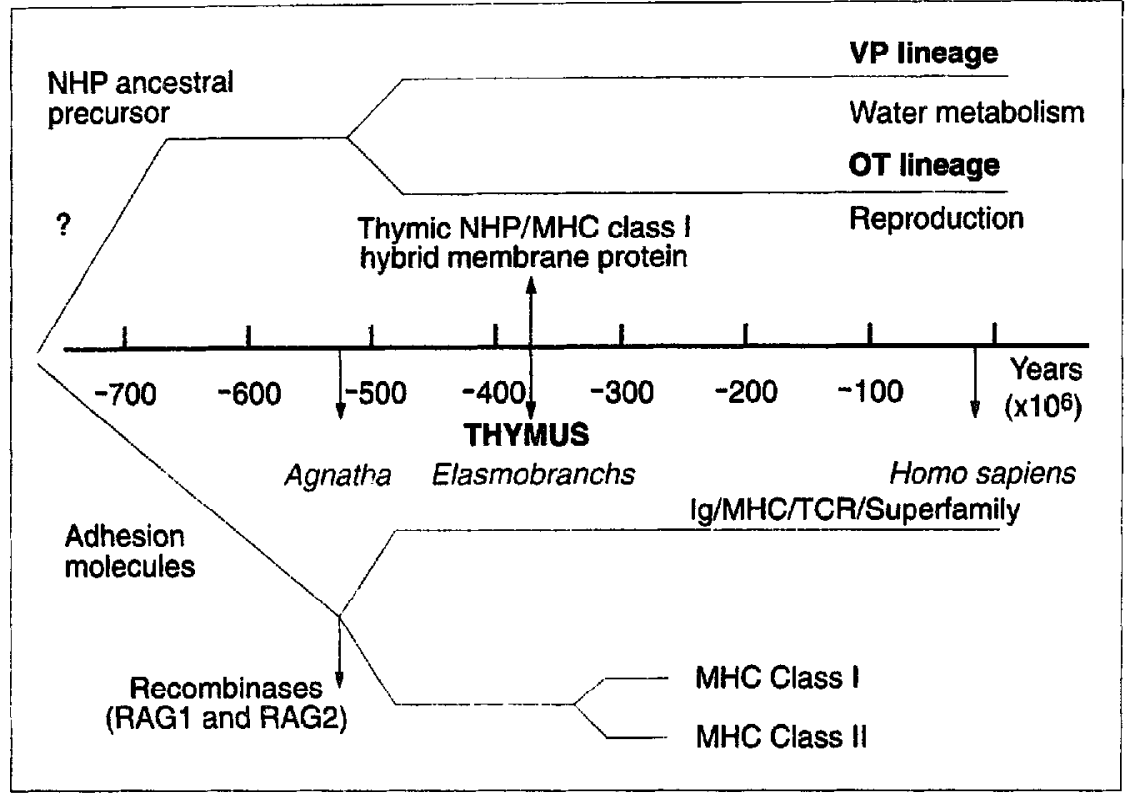

Fig. 3. Parallel evolutions and interactions between the NHP and Ig/MHC/TCR families. The thymic OT chimeric $55 \mathrm{kDa}$ precursor could have appeared after the duplication of the common ancestor of the neurohypophysinl fanily, before or at the same time as the thymic organ. It most probably preceded duplication of MHC-derived proteins in class I and class II, which occurred with the first elasmobranchs. The extreme degree of diversification and the potent properties of molecular recognition chanacterizing most of the members of the Ig/MHC/TCR superfamily originate from random recombination of segment genes coding for Igs or TCRs. Abbrevintions: Ig, immunoglobulin; $M H C$, major histoconpatibility complex; NHP, neurolypophysial; OT, oxytocin; TCR, T-cell receptor; VP, vasopressin.

autocrine signalling (for cells in isolation) and intercellular adhesion (which followed the first cell divisions in the conceptus); (2) the more differentiated steps of paracrine and (neuro)endocrine signalling; and (3) the most advanced forms of synapses in neural networks which have allowed development of cognitive functions. It is assumed that the cryptocrine mode occurs at the rather primitive stage between cell adhesion and paracrine exchanges of soluble signals ${ }^{35}$. In parallel with these distinct structural levels, the components of the genome coding intercellular messengers have evolved to deal with organizational systems of increasing complexity and have been progressively organized into separate families, each containing distinct members in charge of the different types of cell-cell signalling.

Conversely, the immune system has evolved to protect the integrity of self against aggression from infectious nonself. Because of the common peptidic nature of many alloantigens and self-antigens, the immune system must have been educated to recognize and to tolerate the inolecular structure of the internal body. Despite the increasing attention paid to peripheral pathways of T-rell tolerance ${ }^{36}$, the thymus is clearly the primary organ purging the immune system of self-reactive $T$ cells, which could represent a potential threat to survival. The thymic repertoire of neuroendocrine-related self-peptide precursors constitutes an original model that underlines, at the molecular level, the dual role of the thymus in T-cell differentiation (Table 1). According to this model, thymic neuroendocrine-related polypeptide precursors are either the source of accessory signals for positive selection of $T$ cells, or the source of selfpeptides able to induce the negative selection of self-reactive $T$ cells bearing a randomly rearranged TCR oriented against their respective family (Fig. 2). This model concurs with recent reports that have shown that a single peptide may mediate both positive and negative selection of $T$ cells depending on the avidity or affinity of TCR for the peptide used $37,3 \mathrm{n}$

The hypothesis of a phylugenetic continuum also arises from these observations (Fig. 3). As discussed earlier, the NHP family is highly conserved throughout evolution, even in invertebrates. By contrast, the expansion of the immunoglobulin (Ig)/MHC/TCR superfamily began at the level of the primitive vertebrates some 550 million years ago at the latest ${ }^{39}$. Thus, the foundations of the NHP family preceded diversification of the $\mathrm{Ig} / \mathrm{MHC}$ superfamily. The classical feature of neurophysins (two variable sides connected to a greater central constant region) has already been described with the identification of their primary structure $^{40}$, and this constitutes another structural relationship with members of the Ig/MHC superfamily. Moreover, beyond the observation that some structural motifs of the NHP family might have served as guides for further development of the $\mathrm{Ig} / \mathrm{MHC}$ superfamily, it is noteworthy that the thymic OT self-antigen precursor apparently contains both a neuroendocrine- and an MHC class I-related domain. This illustrates the intimacy of cooperation between a classical neuroendocrine family and the $\mathrm{Ig} / \mathrm{MHC} / \mathrm{TCR}$ superfamily, as well as a plausible common ancestral origin of these two families implicated in intercellular signalling and molecular recognition.

This manuscript is dedicated to our mentor and friend, Paul Franchimont, who was a pioneer of radioimmunology in Europe and founded the laboratory where most of these studies have been performed. The advanced stage of this work is greatly indebted to his encouragement and support since its initiation. These studies were supported by grants from the Special Research Fund of the University of Liège Medical School, the Fund for Scientific Medical Research of Belgium, the Association contre le Cancer, the Belgian University Foundation, the International Juvenile Diabetes Foundation, and the European Science Foundation. Our gratitude goes to Prof. J. Urbain (Free University of Brussels) for his generous gift of mAbs to oxytocin, to B. Malgrange (University of Liege) who performed the confocal microscopy analysis of Fig. 1, to A. Godand (INSERM U.437) fur antiserum against leukaemia inhibitory factor, and to $\mathrm{M}$. Wiemann (University of Münster, Germany) who provided us with the ultrastructural image of Fig. 2. 
Henri Martens, Béatrice Goxe and Vincent Geenen are at the University of Liège Medical School, Institute of Pathology CHU-B23, Laboratory of Radio-Immunology and Neuroendocrine-Immunology. B-4000 Sart Tilman, Belgium.

\section{References}

1 Acher, R. (1993) Regul. Peptides 45, 1-13

2 Geenen, V., Legros, J.J., Franchimont, P., Baudrihaye, M.F., Defresne,

M.P. and Boniver, J. (1986) Science 232, 508-511

3 Moll, U.M., Lane, B.L., Robert, F.R., Geenen, V. and Legros, J.J. (1988) Histochemistry 89, 385-390

4 Melis, M.R., Mauri, A. and Argiolas, A. (1995) Regul. Peptides 59, 335-340

5 Robert, F.R., Martens, H., Cormann, N., Benhida, A., Schoenen, J. and

Geenen, V. (1992) Dev. Immunol. 2, 131-140

6 Geenen, V., Vandersmissen, E., Martens, H. et al. (1995) in Neurohypophysis: Recent Progress of Vasopressin and Oxytocin Research (Saito, T., Kurokawa, K. and Yoshida, S., eds), pp. 309-319, Elsevier

7 Geenen, V., Defresne, M.P., Robert, F., Legros, J.J., Franchimont, P. and Boniver, J. (1988) Neuroendocrinology 47, 365-368

8 Wiemann, M. and Ehret, G. (1993) Cell Tissue Res. 273, 79-87

9 Kumamoto, K., Matsuura, T., Amagai, T. and Kawata, M. (1995) Cell Tissue Res. 281, 1-10

10 Funder, J.W. (1990) Mol. Cell. Endocrinol. 70, C21-C24

11 Geenen, V., Robert, F., Martens, H. et al. (1991) Mol. Cell. Endocrinol. 76, C27-C31

12 Martens, H., Robert, F., Legros, J.J., Geenen, V. and Franchimont, P. (1992) Prog. Neuroendocrinimmunol. 5, 31-39

13 Torres, B.A. and Johnson, H.M. (1988) J. Immunol. 140, 2179-2183

14 Elands, J., Resink, A. and De Kloet, E.R. (1990) Endocrinology 126, 2703-2710

15 Caldwell, J.D., Musiol, I.M., Walker, C.H., Pedersen, C.A. and Mason, G.A. (1993) Ann. New York Acad. Sci. 689, 573-577

16 Sugimoto, T., Saito, M., Mochizuki, S. et al. (1995) in Neurolyppoplyysis: Recent Progress of Vasopressin and Oxytocin Research (Saito, T., Kurokawa, K. and Yoshida, S., eds), pp. 409-413, Elsevier

17 Lolait, S. et al. (1995) Proc. Natl Acad. Sci. USA 92, 6783-6787

18 Schaller, M.D., Borgman, C.A., Cobb, B.S., Vines, R.R., Reynolds, A.B. and Parsons, J.T. (1992) Proc. Natl Acad. Sci. USA 89, 5192-5196
19 Bonomo, A. and Matzinger, P. (1993) J. Exp. Med. 177, 1153-1164 20 Townsend, A. and Bodmcr, H. (1989) Annu. Rev. Immunol. 7, 235-238 21 Rammensee, H.G., Falk, K. and Rötzschke, O. (1993) Annu. Rev. Immunol. 11, 213-244

22 Geenen, V., Vandersmissen, E., Martens, H. et al. (1993) Thymus 22, 55-66 23 Griffin, J.H., Alazard, R. and Cohen, P. (1973) J. Biol. Chem. 248, 7975-7978 24 Breslow, E. and Burman, S. (1990) Adv. Enzymol. 63, 1-67

25 Simpson, E., Robinson, P.J., Chandler, P. et al. (1994) Immunology 81, 132-136

26 Ericsson, A., Geenen, V., Robert, F. et al. (1990) Mol. Endocrinol. 4, 1211-1218

27 Geenen, V., Achour, I., Robert, F. et al. (1993) Thymus 21, 115-127

28 Kooijman, R., van Buul-Offers, C., Scholtens, L.E. et al. (1995) J. Immunol $154,5736-5745$

29 Scherbaum, W.A. and Bottazzo, G.F. (1983) Lancet i, 897-901

30 Imura, H., Nakao, K., Shimatsu, A. et al. (1993) New Engl. J. Med. 329, 683-689

31 Cau, P. and Rougon-Capuzzi, G. (1979) Brain Res. 177, 265-271

32 Castano, L. and Eisent, rth, G.S. (1990) Anmu. Rẽ. Immunol. 8 647-649

33 Sheil, J.M., Shepherd, S.E., Klimo, G.F. and Paterson, Y. (1992) J. Exp. Med. 175, 545-552

34 Zapf, J., Walter, H. and Froesch, E.R. (1981) J. Clin. Intest. 68, 1321-1330

35 Geenen, V., Cormann-Goffin, N., Martens, H. et al. (1993) Regul. Peptides 45, 273-278

36 Geenen, V. and Kroemer, G. (1993) Immunol. Today 14, 573-575

37 Sebzda, E., Wallace, V.A., Mayer, J., Yeung, R.S.M., Mak, T.W. and

Ohashi, P.S. (1994) Science 263, 1615-1618

38 Allen, P.M. (1994) Cell 76, 593-596

39 Bartl, S., Baltimore, D. and Weissman, 1.L. (1994) Proc. Natl Acad. Sci. USA 91, 10769-10770

40 Capra, J.D. and Walter, R. (1975) Amn. New York Acad. Sci. 248, 397-407 41 Kramer S., Reynolds, F.H., Jr, Castillo, M., Valenzuela, D.M., Thorikay, M. and Sorvillo, J.M. (1991) Endocrinology 128, 1927-1937

42 Bulloch, K., Radjocic, T., Yu, R., Hausman, J., Lenhard, L. and Baird, S. (1993) Prog. Neuroendocrinimmunol. 4, 186-194

43 Vollmar, A.M. and Schulz, R. (1990) Endocrinology 126, 2277-2281

44 Martens, H., Malgrange, B., Robert, F. et al. Regul. Pept. (in press)

\section{Immunology in other Trends journals}

- Monocyte chemoattractant protein I: a potential regulator of monocyte recruitment in inflammatory disease, B.J. Rollins (1996) Molecular Medicine Today 2 (5), 198-204

- Structure and function of the natural-resistance-associated macrophage protein (Nrampl), a candidate protein for infectious and autoimmune disease susceptibility, J.M. Blackwell (1996) Molecular Medicine Today 2 (5), 205-211

- Gene therapy against cancer and HIV infection using the gene encoding herpes simplex virus thymidine kinase, M. Caruse (1996) Molecular Medicine Todoy 2 (5), 212-217

- Immunoprotection of therapeutic cell transplants by encapsulation, PJ. Morris (1996) Trends in Biotechnology I4 (5), $163-167$

- Human immune response to MSP-I, A.A. Holder and E.M. Riley (1996) Porasitology Today 12 (5), 173-174

- Malaria and onchocerciasis: on HLA and related matters, C.G. Meyer and P.G. Kremsner (1996) Parasitology Today 12 (5), 179-186 